\title{
SISTEMA DE TRAÇÃO ELÉTRICA FLEXÍVEL BASEADO EM VEÍCULOS TRÓLEBUS PARA ALIMENTAÇÃO COM REDES CC E OU CA
}

\author{
Guilherme A. Melo* \\ guiamelo@gmail.com
}

Rodrigo N. Oliveira*

\author{
Moacyr A. G. de Brito* \\ Flávio A. S. Gonçalves*
}

\author{
Carlos A. Canesin* \\ canesinddee. feis.unesp.br \\ ${ }^{*}$ Universidade Estadual Paulista - UNESP \\ Laboratório de Eletrônica de Potência - Departamento de Engenharia Elétrica \\ Ilha Solteira,São Paulo, Brasil
}

\begin{abstract}
This paper presents the main results and the details of methodology and control equations for a single phase $150 \mathrm{~kW}$ pre-regulator rectifier for trolleybus system. The proposed structure allows Power Factor Correction (PFC) with low Total Harmonic Distortion (THD) in the current and in agreement with IEC 61000-3-4 international standards. The results presented in this paper come from a Research, Development and Innovation (R\&D\&I) project with AES Eletropaulo Metropolitana de São Paulo in partnership with Himalaia S.A. transportation company, and the main goal of this work is focused in encouraging the interest for the expansion of trolleybus paths from a platform with lower cost of installation and maintenance, without the DC substation necessity and looking for better quality life in the metropolitan areas of big cities. In this new proposal of power supply system modality, the trolleybus can be powered by both conventional direct current (DC) system and alternate current (AC) from the grid through a Scott transformer, keeping the two wires feeding system with a digital monitoring of the power supply types (DC or AC). Furthermore, the management and control systems are digitally implemented through a XC3S200

Artigo submetido em 16/05/2011 (Id.: 1335)

Revisado em 02/08/2011, 21/11/2011

Aceito sob recomendação do Editor Associado Prof. Francisco de Assis dos Santos Neves
\end{abstract}

FPGA device. Finally, it should be informed that in the evolution of the proposed system, the authors are also working to eliminate the overhead lines using AC power stations specially developed for boarding/landing stations, removing the associated visual disadvantage of this modal, as well as reducing the system operation failures.

KEYWORDS: Electrical vehicles, Trolleybus, Electrical power system distribution for Trolleybus, Electrical energy management, Interleaving boost rectifier, Active power factor correction.

\section{RESUMO}

Este artigo apresenta os principais resultados e o detalhamento da metodologia e equações de controle de um retificador monofásico pré-regulador de $150 \mathrm{~kW}$ para sistema trólebus. A estrutura proposta possibilita a Correção ativa do Fator de Potência (CFP) com baixos níveis de Distorção Harmônica Total (DHT) na corrente, em conformidade com a norma internacional IEC 61000-3-4. Fruto de um projeto de Pesquisa, Desenvolvimento e Inovação (P\&D\&I) junto à empresa AES Eletropaulo Metropolitana de São Paulo, em parceria com a empresa de transporte Himalaia S.A., o projeto possui como principais objetivos estimular o interesse para a expansão das linhas de trólebus a partir de uma plataforma de alimentação de menor custo de instalação e ma- 
nutenção, sem a necessidade de subestações retificadoras, e, com vistas a promover a melhoria da qualidade de vida nos grandes centros urbanos. Nessa nova modalidade proposta para o sistema de alimentação, o trólebus pode ser alimentado tanto pelas redes convencionais em corrente contínua (CC) quanto pelas redes de distribuição em corrente alternada (CA), mantendo-se a disposição a dois fios dos sistemas CC, sendo as mudanças de rede de alimentação (CC ou CA) monitoradas e controladas digitalmente. Todo o sistema de gerenciamento e controle do conversor é realizado digitalmente por FPGA XC3S200. Na evolução do sistema proposto, os autores pretendem inclusive eliminar as linhas aéreas de alimentação, através da utilização de postos de alimentação em CA, especialmente desenvolvidos para os pontos de embarque/desembarque de passageiros para este veículo de transporte coletivo, eliminando-se os aspectos visuais negativos das redes de alimentação deste modal, e, reduzindo-se as falhas de operação do sistema.

PALAVRAS-CHAVE: Veículos Elétricos, Trólebus, Rede de distribuição para sistemas Trólebus, Retificador Boost Entrelaçado, Correção Ativa do Fator de Potência.

\section{INTRODUÇÃO}

Embora a história dos veículos de tração elétrica do tipo Trolébus tenha apresentado momentos de sucesso e de insucesso, este tipo de transporte tem estado em evidência desde sua primeira aparição por volta de 1880 (Brunton, 1992).

As crises do petróleo ocorridas em 1973 e 1979 deixaram claro que as fontes de energia convencionais, baseadas principalmente em combustíveis fósseis, são limitadas e que os países não podem ter suas matrizes energéticas baseadas apenas nestes tipos de combustíveis.

Neste contexto, entre os anos de 1984 a 1986, a equipe de transporte urbano de massa da cidade de São Francisco (Estados Unidos da América) concentrou esforços em um estudo para avaliar as tecnologias de ponta destinadas ao sistema de propulsão dos veículos Trólebus, com a intenção de obter sistemas de alto desempenho (Turner and Guzman, 1986). Ainda, com o intuito de oferecer um serviço de melhor qualidade e com melhor eficientização energética, departamentos de transporte de diversas cidades desenvolveram várias inovações para os veículos Trólebus, economizando energia e melhorando o desempenho de todo o sistema (Martin, 1991; Grosjean, 2009).

A partir desse momento, muitos países vêm substituindo seus sistemas tradicionais de transporte público por sistemas com tração elétrica, demonstrando a eficácia desta opção. Tais ações têm ainda promovido uma importante redução na emissão dos gases de efeito estufa, uma vez que os veículos mo- vidos a eletricidade não produzem gases de escape, são mais eficientes que os movidos por motores a combustão e, ainda, podem ser impulsionados através de fontes de energia alternativas, o que os tornam ainda mais viáveis ecologicamente (Grosjean, 2009).

Embora os sistemas Trólebus apresentem problemas de intrusividade visual devido à distribuição de suas linhas aéreas, soluções modernas com perfis visualmente agradáveis podem ser encontradas e estão sendo praticadas em alguns países. Além disso, com o avanço da tecnologia de acumulação de energia (supercapacitores), vislumbra-se a substituição das linhas aéreas por pontos de conexão de energia elétrica (postos de abastecimento), para alimentação desses acumuladores nos momentos de parada do veículo, para embarque e desembarque de passageiros, associando-se ao sistema a regeneração da energia dos processos de frenagem, para a redução do volume e melhoria da performance dos acumuladores.

Com relação ao consumo de combustível fóssil no país, especialmente para veículos automotores, o crescimento do potencial de exploração de biomassa se torna tão primordial quanto a substituição dos veículos baseados em hidrocarbonetos, especialmente nas grandes regiões metropolitanas. Neste contexto, a substituição dos veículos públicos movidos a diesel por veículos híbridos (diesel e/ou eletricidade), ou por Trólebus (movidos somente por eletricidade) tem se apresentado como um meio em potencial para a redução drástica da emissão de poluentes, tais como: dióxido de carbono, nitrogênio, óxido de nitrogênio e até mesmo a eliminação da emissão de monóxido de carbono.

Considerando os possíveis impactos ambientais, os sistemas Trólebus têm mais benefícios que os sistemas híbridos. Apesar dos custos de operação serem maiores do que os similares a diesel, sua emissão de poluentes é reduzida em 90\%, aliando-se a uma operação silenciosa, vida útil média aproximadamente 4 vezes maior e custos de manutenção $35 \%$ menores (Brunton, 2000), demonstrando o potencial da aplicação.

Devido às melhorias no transporte humano e também de carga, além da minimização do impacto ambiental, onde, nas grandes cidades, a emissão de gases nos níveis atuais é inadequada e não pode ser mais suportada, o sistema Trólebus tem atraído grande atenção de toda a comunidade internacional.

Neste contexto, considerando a experiência acumulada desde 1911, introduzida pelas pesquisas e implementações realizadas na Europa, desenvolver sistemas baseados em Trólebus tem se mostrado como um sofisticado, não poluente, silencioso, rápido e popular meio de transporte urbano. Basicamente, o sistema Trólebus é um ônibus movido a eletricidade e, similarmente aos ônibus convencionais, roda por 
meio de pneus e não sobre trilhos, como na maioria dos veículos elétricos (trens/bondes). Normalmente, a alimentação é realizada em corrente contínua (CC), onde a energia elétrica chega através de hastes, denominadas tecnicamente como alavancas, as quais ficam sobre a carroceria e em contato com a fiação específica. Os Trólebus têm parte de sua estrutura elétrica baseada nos bondes, que nos Estados Unidos são conhecidos como Trolleys.

Desde o início da utilização dos Trólebus, as máquinas CC eram empregadas com o intuito de promover controle de torque e de velocidade. Entretanto, com a evolução do controle das máquinas de corrente alternada (CA), por intermédio da evolução da eletrônica de potência, e, em função das desvantagens apresentadas pelas máquinas CC (elevados peso, volume e custo, incluindo a manutenção), as máquinas CA têm ganhado espaço neste modal de transporte, levando a substituição dos sistemas de conversão CC-CC (Chopers) por sistemas de conversão CC-CA (inversores trifásicos). Entretanto, o sistema de alimentação convencional CC, necessita de uma subestação centralizada, que retifica a energia do sistema de distribuição e na grande maioria das vezes apresenta problemas de qualidade de energia (afundamentos de tensão, altas distorções harmônicas de corrente no lado CA, baixo fator de potência, dentre outros).

Assim, um importante aspecto relacionado à utilização do sistema convencional Trólebus está na dificuldade da expansão do sistema CC atual, em virtude dos custos elevados, das áreas relativamente grandes necessárias para as subestações retificadoras, e, no Brasil, pela deficiência na regulamentação da distribuição em CC, que impede investimentos na expansão das redes CC para a operação de Trólebus por parte das concessionárias de distribuição em CA.

Contudo, considerando uma nova plataforma de alimentação CA para o sistema Trólebus, onde o sistema trifásico de distribuição CA existente poderia suportar a adição destas novas cargas, a expansão das novas linhas para os Trólebus se tornaria mais simples e de menor custo.

A Tabela 1 apresenta os principais custos anuais relativos a uma subestação típica CC para sistemas Trólebus, onde é evidente que a substituição deste tipo de plataforma seria extremamente viável para a redução dos custos e facilidade da expansão deste sistema de transporte.

Entretanto, problemas relativos ao uso desta nova plataforma estão na dificuldade de se transformar uma carga como o Trólebus e seu sistema convencional de alavancas de alimentação a dois fios em sistemas trifásicos (Sopov et alii, 2006), ou deixar que sua elevada carga desbalanceada e geradora de harmônicos seja alimentada apenas por duas fases (Fratta $e t$ alii, 1998; Michalik et alii, 2008).
Tabela 1: Custo Anual para uma Subestação CC típica para sistema Trólebus (AES Eletropaulo)

\begin{tabular}{|l|r|}
\hline Descrição & Custos Anuais(R\$) \\
\hline Manutenção Preventiva Cubículos & $16.285,71$ \\
\hline $\begin{array}{l}\text { Manutenção Preventiva Comando e } \\
\text { Proteção }\end{array}$ & $65.142,86$ \\
\hline Manutenção Preventiva Retificador & $27.750,00$ \\
\hline Manutenção Corretiva Retificador & $36.857,14$ \\
\hline Manutenção Preventiva Disjuntor CC & $81.428,57$ \\
\hline Manutenção Corretiva Disjuntor CC & $30.428,57$ \\
\hline Manutenção Chaves Seccionadoras & $7.125,00$ \\
\hline Total & $265.017,85$ \\
\hline
\end{tabular}

Contudo, esses problemas podem ser muito minimizados com a utilização de um transformador Scott, o qual converte o sistema de alimentação trifásico em dois sistemas monofásicos (Sopov et alii, 2006; Michalik et alii, 2008; Erfranian and Wilsun, 2008). Desta forma, cada um destes sistemas monofásicos poderiam alimentar um conjunto de trólebus, e, com a imposição de formas de ondas senoidais para as correntes drenadas destes sistemas, poder-se-ia impor fator de potência quase unitário para a instalação.

Assim, a nova plataforma proposta associaria o sistema existente, CC tradicional, com o sistema CA de alimentação, sem comprometer a eficiência e a confiabilidade do sistema de acionamento Trólebus. Para tanto, propõe-se a utilização de um transformador Scott para compor o sistema de alimentação a dois fios para o lado trólebus, associado a um conversor retificador pré-regulador, instalado no trólebus, c apaz de identificar apropriadamente o tipo de alimentação (CC ou CA), impondo reduzidos conteúdos harmônicos para a corrente drenada do sistema de distribuição, quando em CA, e, operando com elevada densidade de potência (baixo peso e volume por kilowatt).

Portanto, este artigo apresenta os principais resultados de um projeto de P\&D\&I ,realizado com apoio da AES Eletropaulo Metropolitana Eletricidade de São Paulo S. A., onde se desenvolveu um conversor chaveado para operação de um Trólebus, apresentando correção ativa do fator de potência quando alimentado por redes CA, operando como um retificador monofásico pré-regulador com potência nominal de $150 \mathrm{~kW}$ e em conformidade com a norma internacional IEC61000-3-4 (Gonçalves and Canesin, 2005; Canesin et alii, 2009a,2009b,2009c,2009d).

Finalmente, observa-se que os resultados aqui apresentados contemplam a primeira fase da pesquisa, sendo que, na continuidade, os autores estão evoluindo a estrutura para permitir a eliminação total das redes aéreas, com a alimentação do trólebus ocorrendo unicamente em CA, através de pos- 
tos de abastecimento (com medição em CA e registros adequados), permitindo, dentre outros benefícios, transparência para o processo de composição das tarifas para este modal de transporte público.

\section{NOVO SISTEMA DE DISTRIBUIÇÃO PARA TRÓLEBUS}

A proposta deste artigo está focada na flexibilidade de alimentação em CA ou CC de veículos do tipo Trolebus através de linhas de distribuição aéreas a dois fios, como apresentado na Fig. 1. Para o projeto desenvolvido, a alimentação em CA fornece uma forma de onda de tensão monofásica senoidal com valor nominal de $380 \mathrm{~V}$ eficazes, proveniente de uma rede de distribuição trifásica usando apenas um transformador Scott e um disjuntor para proteção. As subestações convencionais CC provêm tensão com valor médio em torno de 600V. Entretanto, ambos os tipos de subestações podem apresentar mais ou menos 10\% de flutuações nas formas de onda de tensão, em relação aos valores nominais, na rede aérea a dois fios.

Desta forma, o sistema proposto para o estágio de entrada do veículo Trolebus, (RCFP), propicia um barramento CC com níveis adequados de tensão $(600 \mathrm{~V}$ até $720 \mathrm{~V})$ ao sistema de controle de velocidade utilizado pelo veículo, seja ele empregando motores $\mathrm{CA}$ (e, inversores) ou $\mathrm{CC}$ (e, conversores CC-CC), como demonstrado através da Fig. 2.

Quando alimentado pelo sistema de distribuição em CA, o Retificador com Correção do Fator de Potência (RCFP) deve operar provendo regulação adequada para o barramento CC e uma forma de onda de corrente com formato senoidal (níveis adequados de DHT) deve ser drenada da rede; já para a operação com alimentação em CC, o RCFP deve operar como um conversor CC-CC, mantendo o barramento CC em níveis adequados, ou simplesmente ficar desativado quando os níveis de tensão de entrada estiverem em níveis seguros para a operação.

Observa-se que o foco deste trabalho, fase 1, não envolve por completo as características de projeto das novas redes CA para Trólebus, considerando-se que cada saída monofásica do transformador Scott alimentaria circuitos distintos da linha aérea. Desta forma, considerando-se as dinâmicas de operação do sistema, quando da operação em CA, os transformadores Scott adequadamente conectados em função de determinado número de veículos em operação por circuito, tenderiam a suprir cargas equilibradas através de suas duas fases (duas partições da rede aérea) e com correntes drenadas praticamente senoidais. Sendo assim, não haveria a necessidade de técnicas adicionais de compensação reativa ou de mitigação harmônica, tradicionalmente necessárias em siste- mas de tração elétrica (Zanotto et alii, 2005, Czuchra et alii, 2009, Aeberhard et alii, 2010; Ladoux et alii, 2010).

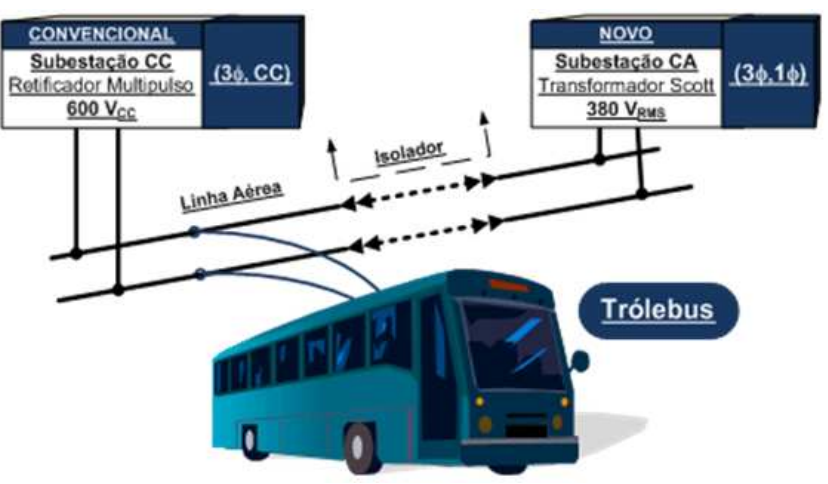

Figura 1: Sistema de Distribuição Proposto para o Sistema Trolebus (CC e/ou AC).

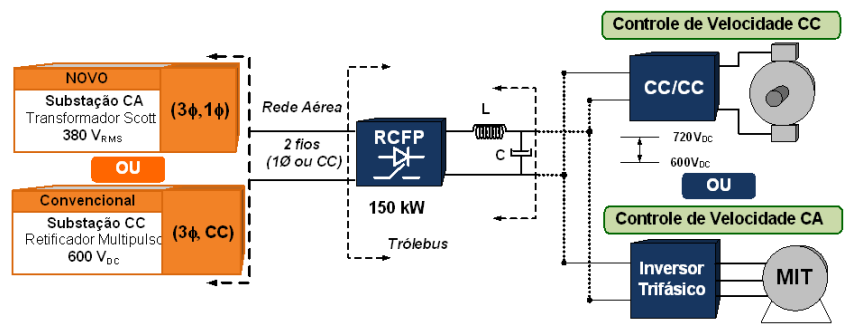

Figura 2: Diagrama de Blocos resumido para o Sistema de Acionamento baseado em Trólebus.

\section{RETIFICADOR BOOST ENTRELAÇADO EM MCD}

A estrutura proposta inclui um retificador não controlado em ponte completa convencional associado a 5 células entrelaçadas de conversores CC-CC Boost, atuando como um RCFP. Com o propósito de garantir as dinâmicas necessárias para o controle do fluxo de potência, o conversor foi projetado para operar no modo de condução descontínua (MCD), tendo como vantagens a simplicidade de controle, robustez e confiabilidade para a estrutura. Apesar do conversor operar no MCD, a corrente de entrada é contínua e apresenta baixos níveis de distorção harmônica. Isso é possível devido a utilização da técnica de entrelaçamento associada a uma compensação especial da forma de onda da corrente de entrada, promovendo corrente de entrada praticamente senoidal. É necessário salientar que, devido ao baixo ganho estático do conversor Boost, apenas o entrelaçamento não garante baixa DHT para a corrente de entrada, sendo fundamental a utilização de uma técnica de correção especial aplicada à corrente, a qual será apresentada neste artigo. 
Na Fig. 3 é possível observar detalhes do retificador Boost entrelaçado cuja potência nominal é de $150 \mathrm{~kW}$. Os dados de entrada e de saída, incluindo os parâmetros de projeto e componentes utilizados para o protótipo de escala nominal estão resumidos na Tabela 3.

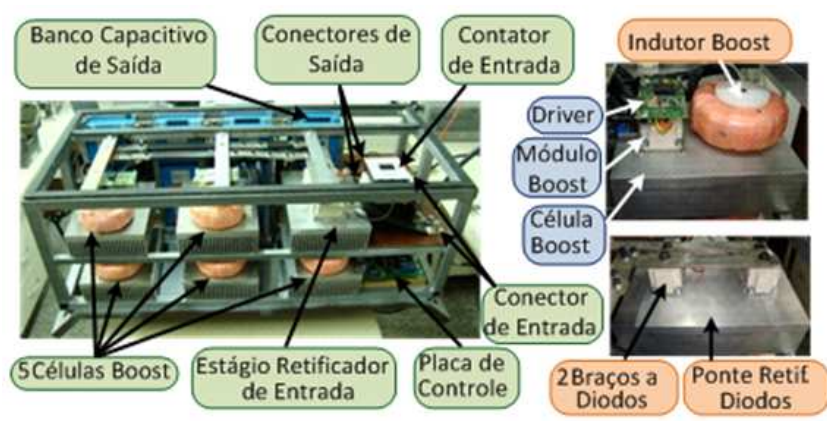

Figura 3: Retificador Boost Entrelaçado com suas 5 células.

Tabela 2: Dados de Projeto e Parâmetros para o Retificador Pré-Regulador Boost Entrelaçado

\begin{tabular}{|l|l|}
\hline \multicolumn{2}{|l|}{ Dados de Entrada e de Saída } \\
\hline Parâmetro & Valor \\
\hline$V_{i n[C A]}$ ou $V_{i n[C C]}$ & $380 \mathrm{~V}$ (eficaz) ou 600V(médios) \\
\hline$V_{0}$ & $680 \mathrm{~V}$ \\
\hline$P_{0}$ & $150 \mathrm{~kW}$ \\
\hline$f_{s}$ & $20 \mathrm{kHz}$ \\
\hline Número de Células (i) & 5 \\
\hline Ângulo de defasagem [rad] & $\pi / 5$ \\
\hline \hline Parâmetros do Circuito \\
\hline Parâmetro & Especificação \\
\hline$S_{P-i}$ e $D_{i}$ & Modulo SKM400GAL128-D \\
\hline $\begin{array}{l}\text { Ponte Retificadora de En- } \\
\text { trada }\end{array}$ & Modulo SKKD380 \\
\hline $\begin{array}{l}L_{-i} \text { (núcleo toroidal - pó de } \\
\text { ferro, T520-34D) }\end{array}$ & $11,8 \mu \mathrm{H}$ \\
\hline $\begin{array}{l}C_{0} \quad(\text { Capacitor de Filme) } \\
\text { PCC-LP/800V }\end{array}$ & $24 / / 600 \mu \mathrm{F}(14,40 \mathrm{mF)}$ \\
\hline
\end{tabular}

\section{ESTRUTURAS E LÓGICAS DE CON- TROLE DESENVOLVIDAS}

A Fig. 4 apresenta o diagrama de blocos simplificado do algoritmo de controle digital desenvolvido, onde os controles de monitoramento, partida suave, e proteções (sobre temperatura, sobre tensão, sobre corrente e curto-circuito) estão suprimidos.

Basicamente, o algoritmo de controle principal é realizado por três estágios intermediários e que atuam simultaneamente, citando: regulação da tensão de saída, correção da

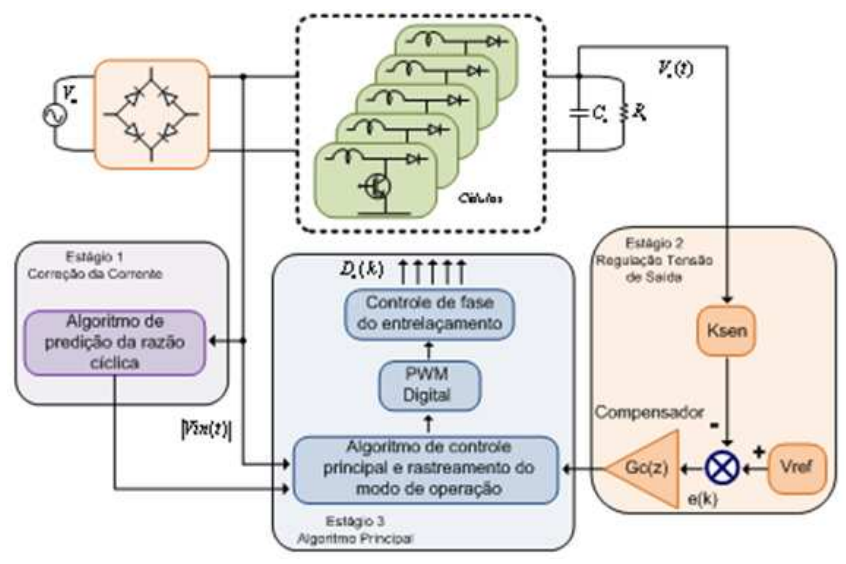

Figura 4: Diagrama de Blocos do Controle Proposto.

corrente de entrada e rastreamento do modo de operação. Todo o controle digital foi implementado usando um dispositivo FPGA XC3S200 de baixo custo, dois sensores de tensão de efeito Hall (LEM LV25-P) e dois conversores do tipo analógico-digital de 8 bits do tipo aproximações sucessivas (AD7810). O algoritmo de controle foi desenvolvido usando a lógica de descrição de hardware VHDL em conjunto com os núcleos parametrizáveis de somadores e registradores da biblioteca SystemGenerator, utilizando lógica aritmética de ponto fixo. Os filtros digitais foram implementados usando a representação direta de sua equação a diferenças no plano z. Após a implementação, toda a lógica VHDL ocupou $72 \%$ dos recursos totais do dispositivo.

\subsection{Modelação e Obtenção das Funções para o Controle do Conversor Boost Entrelaçado}

Considerando o conversor Boost entrelaçado com as suas $\mathrm{n}$ células, operando no MCD, é possível obter a média da derivada da variável de estado tensão sobre o capacitor de saída $\left(\overline{\dot{v}_{c}}\right)$, obtida através de (1).

$$
\overline{\dot{v}_{c}}=\frac{\overline{i_{D}} \cdot n}{C} \cdot d_{2}-\frac{\overline{v_{c}}}{R_{0} \cdot C_{0}}
$$

A partir das etapas de carga e de descarga da corrente no indutor Boost, considerando uma célula genérica, o intervalo de condução da corrente do diodo $\left(\mathrm{d}_{2}\right)$ é obtido em função da razão cíclica, sendo expresso por (2) .

$$
d_{2}=\frac{v_{i n}}{v_{c}-v_{i n}} \cdot d
$$


Adicionalmente, utilizando o intervalo de transferência de potência para a carga, e, considerando que a forma de onda de corrente no diodo é praticamente um triângulo, pode-se obter a corrente média neste elemento através de (3) .

$$
\overline{i_{D}}=\frac{v_{i n}^{2} \cdot d^{2} \cdot T_{s}}{2 \cdot L \cdot\left(v_{c}-v_{i n}\right)}
$$

Substituindo (2) e (3) em (1) , a média da derivada da variável de estado tensão no capacitor de saída pode ser reescrita em função de parâmetros invariantes, como mostrado por (4) .

$$
\overline{\dot{v}_{c}}=\frac{v_{i n}^{2} \cdot d^{2} \cdot T_{s}}{2 \cdot L \cdot C \cdot\left(\overline{v_{c}}-v_{i n}\right)}-\frac{\overline{v_{c}}}{R_{0} \cdot C_{0}}
$$

Observa-se que a expressão (4) pode ser apresentada como uma função de parâmetros, conforme (5) .

$$
\dot{v}_{c}=F\left(v_{c}, V_{i n}, d\right)
$$

Desta forma, a equação a pequenos sinais do conversor Boost entrelaçado se torna como em (6) .

$$
\begin{aligned}
& \hat{\dot{v}}_{c}=A^{\prime} \hat{v}_{c}+B^{\prime} \hat{v}_{i n}+K \hat{d} \\
& A^{\prime}=\frac{\partial F}{\partial v_{c}}, B^{\prime}=\frac{\partial F}{\partial v_{i n}}, K=\frac{\partial F}{\partial d}
\end{aligned}
$$

Considerando-se nulas as variações a pequenos sinais na tensão de entrada, a função de transferência da variável de controle em função da razão cíclica é dada por (7) (Erickson and Maksimovic, 2001).

$$
\frac{\hat{v}_{c}}{\hat{d}}=\left(s I-A^{\prime}\right)^{-1} K
$$

Portanto, pode-se obter a função de transferência $\mathrm{G}_{v d}(\mathrm{~s})$, que representa as variações a pequenos sinais na tensão de saída na presença de variações a pequenos sinais na razão cíclica, sendo esta apresentada em (8) .

$G_{v d}(s)=\left(\frac{V_{i n}^{2} \cdot D \cdot T_{s}}{L \cdot C\left(\bar{v}_{c}-V_{i n}\right)}\right) \cdot\left(\frac{1}{s+\frac{1}{R_{0} \cdot C_{0}}+\frac{V_{i n}^{2} \cdot D^{2} \cdot T_{s}}{2 \cdot L \cdot C\left(\bar{v}_{c}-V_{i n}\right)^{2}}}\right)^{-1}$

A razão de conversão (M), ou ganho estático em $\mathrm{MCD}$, pode ser obtida multiplicando a expressão (3) pela resistência de carga $\left(\mathbf{R}_{0}\right)$ e dividindo pela tensão de entrada. Com isto obtém-se a razão de conversão (9) em função ainda do próprio M. Usando a expressão (9) é possível simplificar (8)
, obtendo-se $\mathrm{G}_{v d}(\mathrm{~s})$ em função da razão de conversão no MCD, explicitada por (10) .

$$
M=\frac{D^{2} \cdot T_{s} \cdot R_{0}}{2 \cdot L \cdot(M-1)}
$$

$$
G_{v d}(s)=\left(\frac{V_{i n} \cdot 2 M \cdot(M-1)}{D \cdot(2 M-1)}\right) \cdot\left(1+\frac{s}{\frac{1}{R_{0} \cdot C_{0}} \cdot\left(\frac{2 M-1}{M-1}\right)}\right)^{-1}
$$

\subsection{Técnica para a Correção da Corrente de Entrada}

A partir da operação do conversor Boost CC-CC operando em MCD, a corrente de entrada média pode ser definida em cada período de chaveamento pelo seu valor médio instantâneo $\left(\hat{i}_{i n}\right)$, como definido em (11); onde o primeiro termo representa a corrente média que circula pelo transistor e o segundo representa a corrente média que circula pelo diodo Boost.

$$
\widehat{i}_{i n}=\frac{D^{2} \cdot T_{s}}{2 \cdot L} \cdot \widehat{v}_{i n}+\frac{D^{2} \cdot T_{s}}{2 \cdot L} \cdot \frac{\widehat{v}_{i n}{ }^{2}}{V_{0}-\widehat{v}_{i n}}
$$

Onde: $\mathrm{T}_{s}$ é o período de chaveamento;

D é a razão cíclica;

$\mathrm{L}$ representa a indutância Boost;

$\widehat{v}_{i n}$ é a média instantânea da tensão de entrada

Considerando-se que a tensão de entrada apresenta formato senoidal e, manipulando-se a expressão (11) é possível observar claramente que a corrente de entrada média apresentada em (12) não apresenta característica senoidal quando a razão cíclica D é constante. Na Fig. 5 é possível observar a corrente de entrada e suas parcelas de correntes que circulam nos semicondutores de um conversor Boost operando no MCD, quando o ganho de conversão estático situa-se próximo da unidade.

$$
\widehat{i}_{i n}=\frac{D^{2} \cdot T_{s} \cdot V_{0}}{2 \cdot L} \cdot \frac{\widehat{v}_{i n}}{V_{0}-\widehat{v}_{i n}}
$$

Manipulando a expressão (11) fica claro que se o sistema de controle for capaz de manter $\left(\mathrm{D}_{e q}\right)$ constante, a corrente de entrada se tornará senoidal, assim como demonstrado por (13) . 


$$
\widehat{i}_{i n}=\frac{D_{e q} \cdot T_{s}}{2 \cdot L} \cdot \widehat{v}_{i n}
$$

Onde:

$$
\begin{aligned}
D_{e q} & =D \cdot\left(D+D_{2}\right) \\
\ldots D_{2} & =D \frac{\widehat{v}_{i n}}{V_{0}-\widehat{v}_{i n}}
\end{aligned}
$$

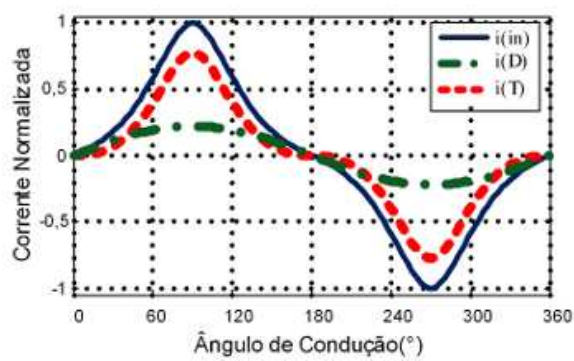

Figura 5: Correntes Relacionadas na Equação (11): i(in) Corrente Normalizada, (i(D)) Parcela de Corrente do Diodo e i(T) Corrente do Transistor.

Para a simplificação da implementação do algoritmo de controle da corrente de entrada é possível manipular (13) obtendo-se (14). Assim, reduz-se o número de slices (células lógicas) necessários do dispositivo FPGA. Basicamente, esta lei de controle é derivada a partir do comportamento da corrente de entrada média sobre cada período de chaveamento, fazendo com que o lado direito de (11) se mantenha constante através da variação da razão cíclica, e, usando (14) ao longo de todo o período CA da tensão de alimentação de entrada, quando o conversor opera como RCFP, compensam-se as variações nas amplitudes da tensão de entrada.

$$
d=\frac{D_{\max }}{\sqrt{V_{0}}} \sqrt{V_{0}-\widehat{v}_{i n}=K \cdot \sqrt{V_{0}-\widehat{v}_{i n}}(14)}
$$

Dessa forma, a maior desvantagem relacionada a não adequação à norma IEC 61000-3-4, devido ao aumento significativo de harmônicos de baixa ordem do conversor Boost entrelaçado em MCD, quando o mesmo opera com ganho estático próximo da unidade, é eliminada.

\subsection{Regulação da Tensão de Saída com Correção Antecipativa da Corrente de Entrada}

A malha de controle de tensão, apresentada na Fig. 6, é responsável por assegurar o valor efetivo da tensão média de saída e também inclui a correção da corrente. Essa malha de controle apresenta os ganhos dos sensores, o compensador de tensão, a malha de corrente antecipativa (feed-forward) e a planta de tensão do conversor.

A regulação da tensão de saída é baseada em um compensador proporcional-integral convencional (PI) realizando um controle em modo tensão e de baixa frequiência. Este controlador possui um pólo na origem e sintonia em duas oitavas abaixo da frequência do mínimo pólo da carga, sendo o ganho proporcional determinado a partir do ganho de malha $\mathrm{T}_{v}(\mathrm{~s})$. A determinação do ganho proporcional é realizada com a utilização da carga nominal, igualando-o ao ganho de malha $\mathrm{T}_{v}(\mathrm{~s})$ na frequência de cruzamento.

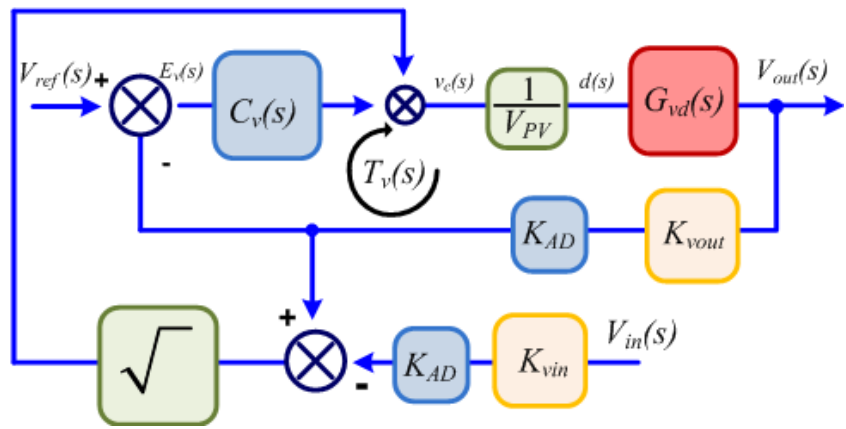

Figura 6: Diagrama de Blocos da Malha de Controle de Tensão com o Ganho de Malha Tv(s).

O controlador obtido é apresentado em (15) para uma taxa de amostragem de $20 \mathrm{kHz}$, onde um método de "discretização" de equações lineares, denominado método Tustin, foi utilizado, sendo os parâmetros da equação apresentados na Tabela 3 (Tustin, 1947).

$C_{v}(z)=\left.K_{P} \frac{s+\left(K_{i} / K_{p}\right)}{s}\right|_{s=\frac{2}{T_{S}} \frac{z-1}{z+1}}=\frac{12,01 z-11,99}{z-1}$

Tabela 3: Parâmetros do Laço de Controle

\begin{tabular}{|l|l|}
\hline Parâmetro & Valor \\
\hline $\mathrm{K}_{p}$ & 12 \\
\hline $\mathrm{K}_{i}$ & 2580 \\
\hline $\mathrm{V}_{p v}$ & 500 \\
\hline $\mathrm{K}_{\text {vout }}$ & $3 / 750$ \\
\hline $\mathrm{K}_{\text {vin }}$ & $3 / 750$ \\
\hline $\mathrm{K}_{A D}$ & 1 \\
\hline
\end{tabular}

O diagrama de Bode da função de transferência de malha aberta de tensão, incluindo a malha de corrente antecipativa e com o compensador PI projetado é apresentado na Fig. 7. Observa-se que o sistema apresenta margem de fase adequada mantendo excelente estabilidade, com frequência de 
cruzamento de ganho em torno de $8 \mathrm{~Hz}$ e a margem de fase em $70^{\circ}$.

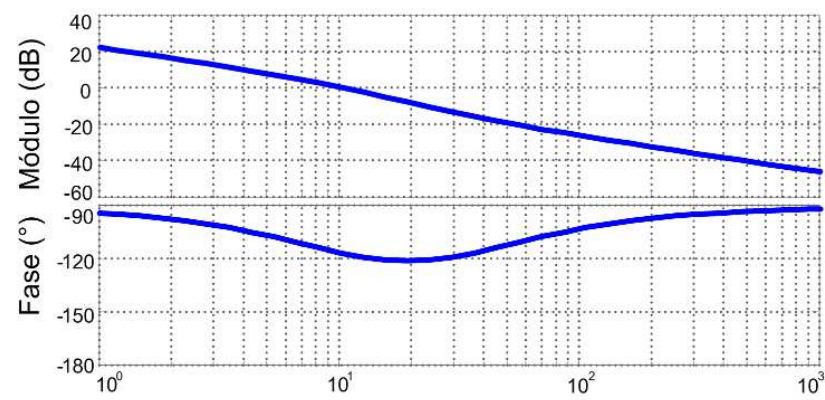

Figura 7: Diagramas de Bode do Sistema com Controlador e Malha Feed-forward.

Os sobre sinais transitórios presentes na tensão de saída são características críticas típicas da operação no modo descontínuo quando o conversor Boost entrelaçado opera no modo tensão. Devido à baixa velocidade da malha de controle e ainda devido a tensão de saída regulada estar muito próxima da máxima tensão permitida $(720 \mathrm{~V})$, problemas operacionais poderiam surgir. Desta forma, o compensador PI convencional pode não apresentar os requisitos desejados para os transitórios quando em remoção crítica de carga. Assim, a estratégia de controle e compensação baseada no compensador PI foi modificada. Durante os transitórios, quando a tensão de saída instantânea supera 710 volts, o ganho de malha $\mathrm{T}_{v}(\mathrm{~s})$ é modificado por uma função de transferência $\mathrm{G}_{a d p}(\mathrm{~s})$ de forma a aumentar o erro e a frequência de cruzamento de ganho da malha, fazendo com que as respostas transitórias sejam aceleradas. Além disso, quando cessa o transitório, o ganho de malha volta para seu valor inicial de projeto. O processo de retorno do ganho de malha não reflete em transitórios severos na tensão de saída, uma vez que o erro de tensão é muito pequeno nessa situação.

A Fig. 8 apresenta o diagrama de blocos modificado, no qual a função $\mathrm{G}_{a d p}(\mathrm{~s})$ insere a não linearidade no ganho de malha relativo à tensão de saída instantânea. A estratégia de ajuste do ganho é visualizada através da Fig. 9, onde os parâmetros $\Delta 1$ e $\Delta 2$ são configurados com os níveis de tensão em $15 \mathrm{~V}$ e $5 \mathrm{~V}$, respectivamente.

As Figs. 10 e 11 mostram resultados de simulação dos transitórios presentes na tensão de saída relativos a um degrau de carga, da nominal $(150 \mathrm{~kW})$ para carga nula, considerando o compensador PI convencional e o compensador não-linear proposto.

É necessário salientar que com o compensador PI convencional, o sobre-sinal apresentado alcança o patamar de 780V, ultrapassando a tensão máxima permitida pela aplicação $(720 \mathrm{~V})$. Entretanto, usando o compensador não linear pro-

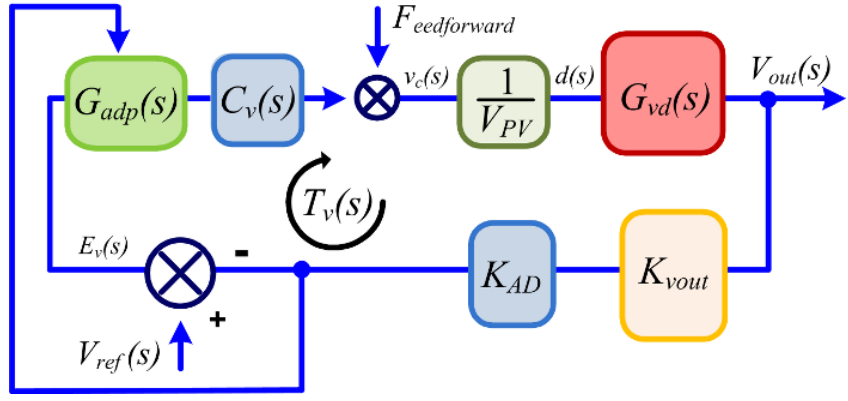

Figura 8: Diagrama de Blocos Modificado para o Controle do Conversor.

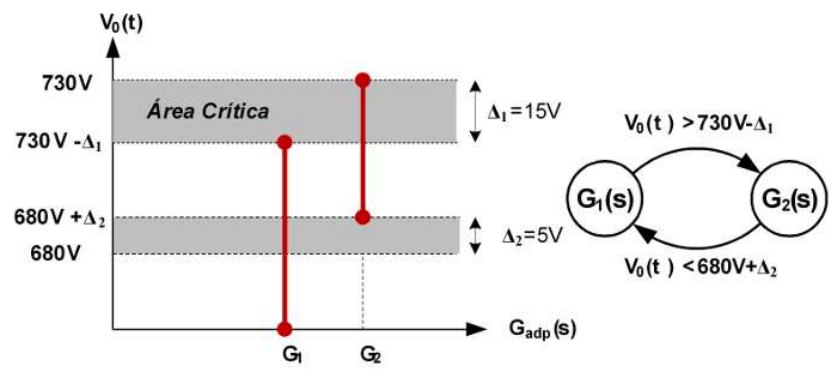

Figura 9: Estratégia de Ajuste de $\mathrm{G}_{a d p}(\mathrm{~s})$ no Ganho de MaIha.

posto, os transitórios permaneceram abaixo do valor limite, garantindo eficácia para a operação segura.

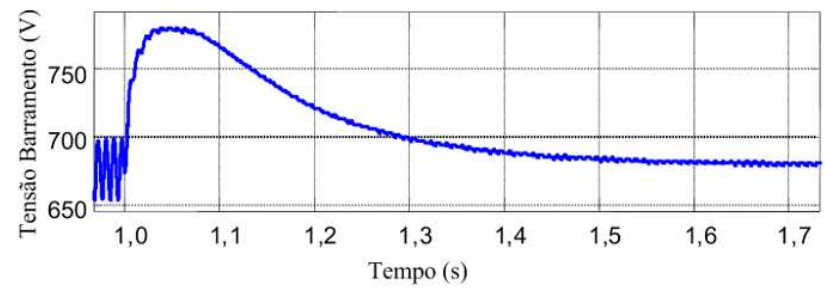

Figura 10: Tensão de Saída Durante Transitório de Retirada de Carga (150kW - carga nula), Considerando Compensador Convencional.

\subsection{Redes CA ou CC - Rastreamento dos modos de Operação}

A nova plataforma de distribuição de energia proposta para os veículos Trolebus, considerando alimentação em CC (trechos antigos) e em CA (trechos novos), fará com que a forma de onda da tensão de alimentação para o veículo, durante a operação do mesmo nas linhas aéreas de distribuição, seja alterada de CA para CC e vice-versa. Adicionalmente, durante o processo de troca de rede de alimentação (separador isolador), existe um intervalo no qual o sistema de alimentação do Trolebus fica desconectado da rede resultando numa tensão nula de alimentação para o RCFP. Normalmente, a distância entre o ponto de interligação das linhas aéreas, quando da 


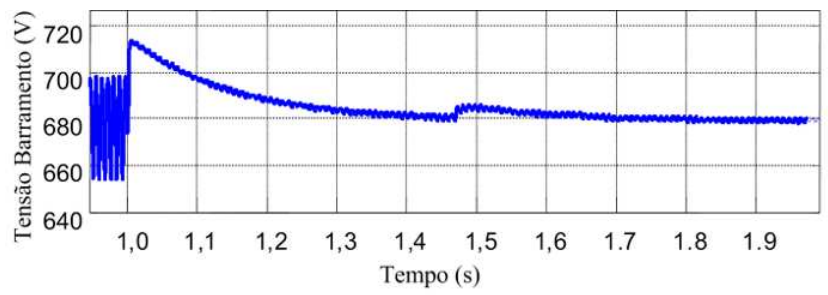

Figura 11: Tensão de Saída Durante Transitório de Retirada de Carga (150kW - carga nula), Considerando o Compensador Não-Linear Proposto.

mudança de modo de operação, é da ordem de 40 a $80 \mathrm{~cm}$, e o veículo executa esta trajetória com velocidades variando entre $5 \mathrm{~km} / \mathrm{h}$ até $80 \mathrm{~km} / \mathrm{h}$. Assim, o algoritmo de rastreamento do modo de operação deve ter uma resposta consistente e com tempo menor do que o tempo necessário para o veículo comutar entre as linhas aéreas, isto para o pior caso a fim de que o sistema de controle possa realizar as operações necessárias.

Apesar das características próprias de cada modo de operação, sejam eles CA ou CC, seus valores médios retificados apresentam grandes diferenças, com aproximadamente $342 \mathrm{~V}$ para o caso CA e para o caso CC com 600V. Desta forma, o algoritmo desenvolvido não pode simplesmente usar o valor médio ou o cruzamento por zero da tensão para detectar os modos de operação. É importante destacar que oscilações na tensão de entrada (da ordem de $20 \%$ ) e severos transitórios, como por exemplo, quando os coletores do veículo são desconectados da rede aérea, podem levar à determinação incorreta de cada modo de operação. Assim, a metodologia aplicada para o rastreamento dos modos de operação se baseia não somente no valor médio da tensão retificada de entrada mas também no valor médio da diferença entre a tensão média retificada $\left(\overline{V_{i n}(t)}\right)$ e seu valor instantâneo retificado $\left(\left|V_{i n}(t)\right|\right)$, denominada por $V_{X}(t)$, resultando na determinação consistente do modo de operação.

As variáveis utilizadas pelo algoritmo de detecção são apresentadas na Fig. 12, onde apresenta-se um caso de troca de linhas aéreas, primeiramente de $\mathrm{CA}$ para $\mathrm{CC}$ e posteriormente de CC para CA.

Nesta simulação foram adicionados certos níveis de interferência na forma de onda da tensão de entrada, a fim de representar um modelo mais fiel ao enfrentado pelos veículos nas redes aéreas de distribuição usuais. É possível observar que para cada transição, existem bordas de subida e de descida dentro da forma de onda média. Ademais, quando o modo de operação é CA, a forma de onda $\mathrm{V}_{X}$ apresenta característica pulsante, mas mantém baixa amplitude quando no modo CC.

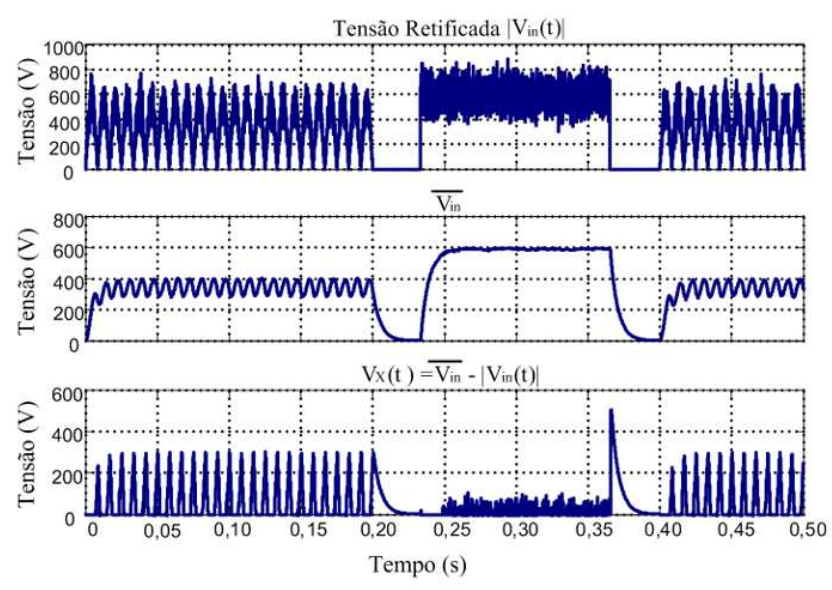

Figura 12: Formas de Onda Relacionadas com a Resposta do Algoritmo de Rastreamento dos Modos de Operação (CA para CC e CC para CA).

Considerando-se os custos relacionados com o aumento do número de células lógicas quando da implementação de algoritmos de controle via FPGA, é interessante reduzir e simplificar os blocos de controle de forma a maximizar a utilização da pastilha. Por este motivo, um filtro digital modificado Butterworth de primeira ordem, com taxa de amostragem de $20 \mathrm{kHz}$, foi escolhido para implementar os valores médios das grandezas. A equação a diferenças deste filtro é apresentada em (16) .

$$
G_{\text {modo_ope }}(z)=\frac{5,7318-5,7304 \cdot z^{-1}}{1-z^{-1}}
$$

\section{RESULTADOS DE SIMULAÇÃO}

A ferramenta computacional utilizada para as simulações foi o software Simulink $\AA$, presente no ambiente MatLab $₫$, no qual é possível modelar e analisar a dinâmica de sistemas, possibilitando a integração de projetos de potência com projetos de controle de forma simples e eficaz. As simulações foram realizadas utilizando-se de um modelo chaveado para o estágio retificador pré-regulador boost entrelaçado, através da biblioteca Sympowersystems, a fim de se obter resultados mais precisos. Na Fig. 13, apresenta-se todo o circuito simulado, incluindo o modelo construído, as estratégias de controle e de modulação. Os parâmetros de projeto utilizados na simulação encontram-se nas Tabelas 2 e 3.

Nas Figs. 14, 15, 16 podem ser observadas a forma de onda da corrente drenada do sistema de alimentação, a tensão de saída e a partida suave aplicada ao estágio pré-regulador retificador entrelaçado. Verifica-se a qualidade da compensação de corrente efetuada, apresentando um baixo conteúdo harmônico e por consequência alto fator de potência para a estrutura. A tensão de saída está regulada e estabilizada no 


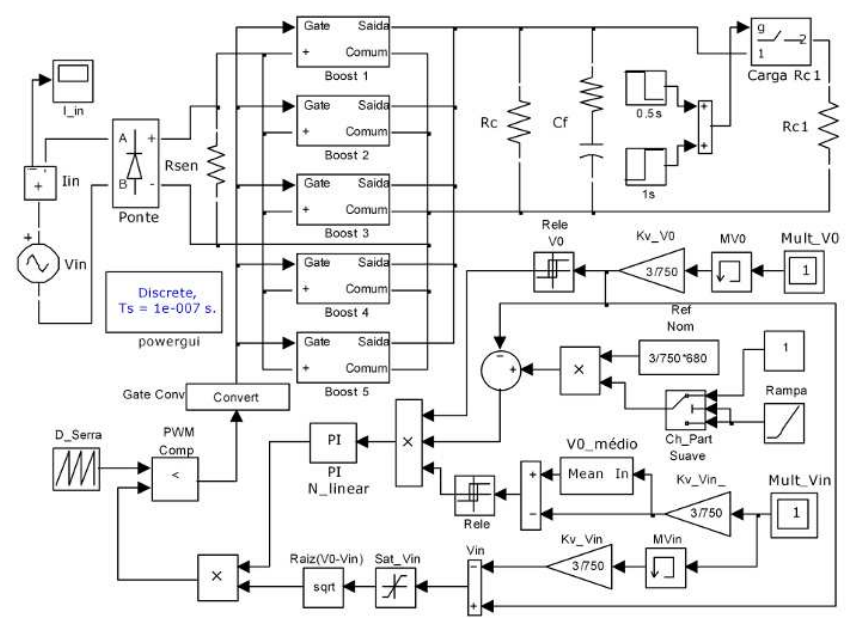

Figura 13: Modelo para Simulação do Conversor no Ambi-

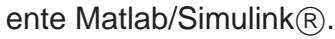

valor de projeto, e, a partida suave garante a inicialização adequada do sistema.

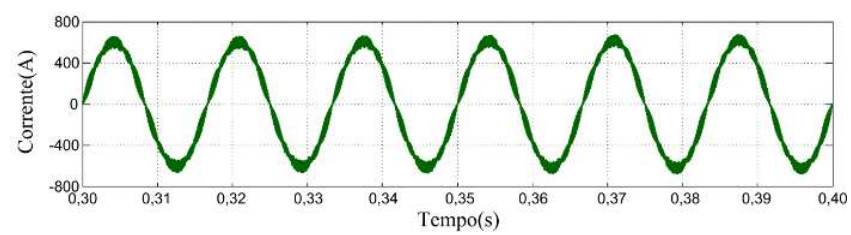

Figura 14: Corrente de Entrada Drenada da Rede AC.

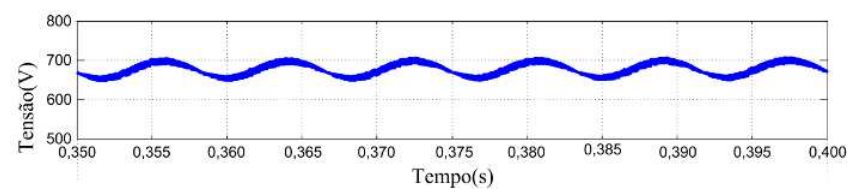

Figura 15: Tensão de Saída do Conversor.

\section{RESULTADOS EXPERIMENTAIS}

O protótipo foi adequadamente desenvolvido e implementado com o propósito de se adaptar às dimensões mecânicas do espaço reservado para o mesmo na lateral do Trólebus utilizado para os testes de campo, conforme Fig. 17, evitando-se maiores problemas mecânicos e dimensionais durante a fase de montagem e implementação da estrutura final.

Os testes nas redes CA e CC foram realizados na cidade de São Paulo (SP), de acordo com o percurso apresentado na Fig. 18, no qual o veículo alcançou a rede de distribuição CA a partir da rede $\mathrm{CC}$ convencional.

A Fig. 19 mostra o arranjo experimental composto pelo sistema de aquisição de dados "wavebook"da iOtek com uma ponteira de corrente Yokogawa $10 \mathrm{mV} / \mathrm{A}$ para medição da corrente de entrada do sistema e um sensor do tipo Hall de

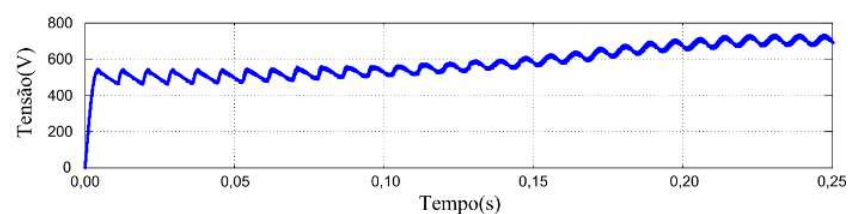

Figura 16: Partida Suave para o Estágio Retificador PréRegulador.
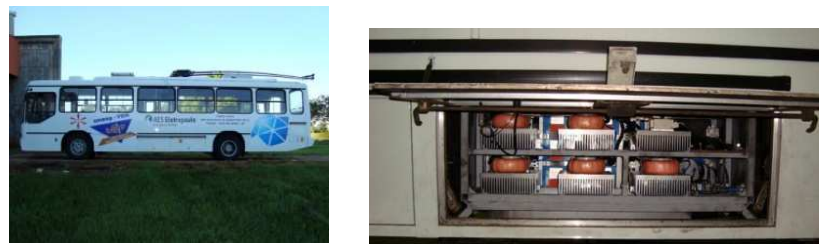

Figura 17: (a) Trólebus utilizado para os Testes de Campo; (b) Conversor proposto de 150kW instalado no Trólebus.

500A para a medição da corrente de saída. Nesta figura é apresentado um computador portátil com programas específicos da Xilinx (Project Navigator e ChipScope), com o qual foi possível reprogramar e supervisionar em tempo real o dispositivo FPGA empregado (Spartan XC3S200).

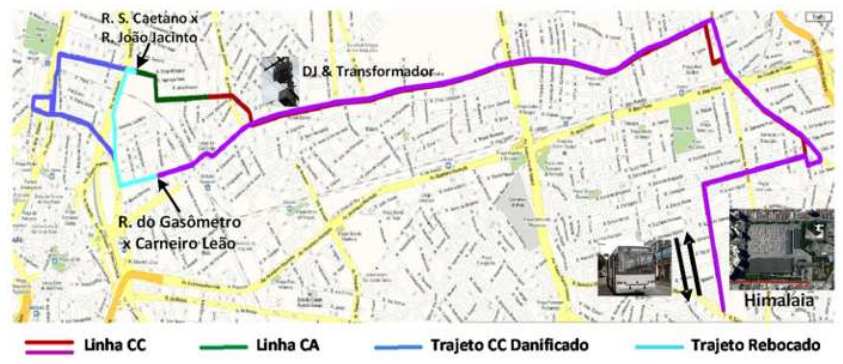

Figura 18: Rota do Veículo Trólebus, incluindo Redes de Distribuição CA e CC.

Algumas variações elevadas de carga foram observadas durante o trajeto do Trólebus e, uma visão geral destas formas de onda podem ser visualizadas na Fig. 20; com detalhes positivos e negativos para estas variações sendo visualizados de forma mais clara nas Fig. 21 e 22, onde a tensão de entrada $\left(\mathrm{V}_{\text {in }}\right)$, a tensão de saída $\left(\mathrm{V}_{\text {out }}\right)$, a corrente de entrada $\left(\mathrm{I}_{i n}\right)$ e de saída $\left(\mathrm{I}_{\text {out }}\right)$ são apresentadas. Através destas figuras pode-se observar que a forma de onda da corrente drenada da rede sempre mantém o formato senoidal, seja com baixa ou elevada potência demandada pelo Trólebus, durante sua operação em trânsito normal e em dia de semana na cidade de São Paulo(SP).

A Fig. 23 apresenta as formas de onda gerais de tensão e de corrente de um dia típico de tráfego na rede de distribuição CA. Alguns eventos recorrentes presentes na Fig. 23 são observados com detalhes: Fig. 24(a) apresenta um desligamento do conversor devido a uma ação de controle para proteger o sistema; Fig. 24(b) mostra um pico de variação 


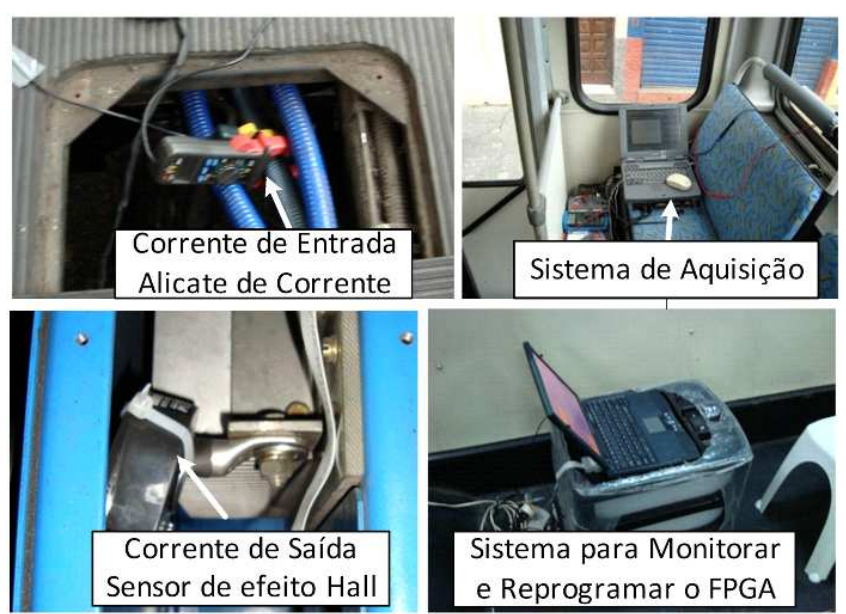

Figura 19: Sistema de Aquisição Embarcado no Veículo.
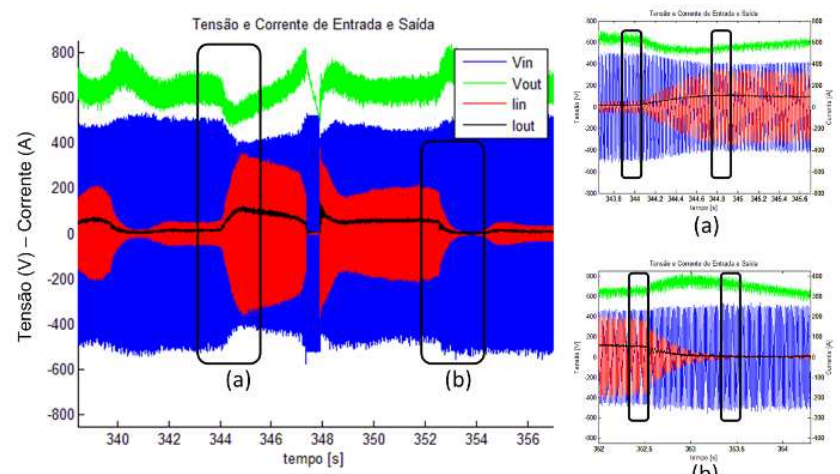

(a)

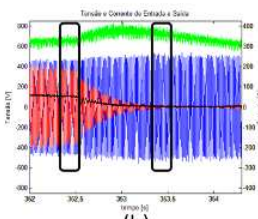

(b)

Figura 20: Operação normal do Trólebus: Degraus Positivos e Negativos de Carga.

de carga devido a aceleração do veículo; Fig. 24(c) e (c1) apresentam um degrau de carga devido ao desligamento do compressor do Trólebus.

Os próximos resultados se referem a mudanças entre tipos de redes de distribuição, considerando-se neste artigo apenas a transição de CA para CC como a comutação mais severa a ser investigada e testada. Observa-se que a comutação de CC para $\mathrm{CA}$, em campo, não foi testada em função da danificação de trecho de rede da AES-EletroPaulo à época dos testes.

A Fig. 25 apresenta uma transição entre a rede CA e CC, no qual o motorista do veículo Trolebus tem que desacelerar para manter a mínima carga possível quando o veículo passa pela região sem nenhum tipo de alimentação. Durante este intervalo, a tensão CC de saída do conversor permanece quase constante e se torna praticamente a mesma quando o conversor é alimentado, posteriormente, com a rede de distribuição CC.

Uma carga relativamente elevada (em torno de $85 \mathrm{kVA}$ ) foi observada em operação e está apresentada na Fig. 26, onde
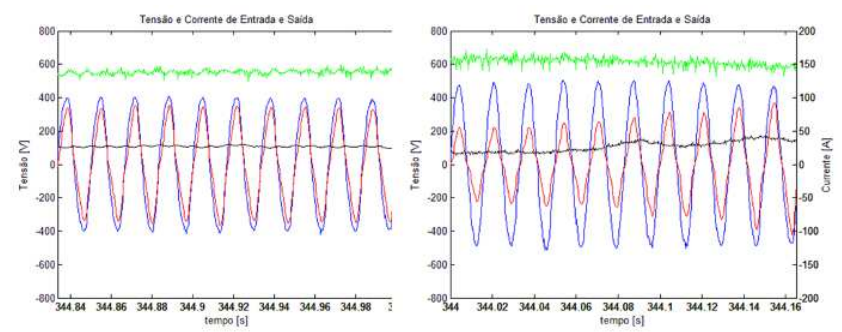

Figura 21: Formas de Onda para o Detalhe Positivo de Variação de Carga.
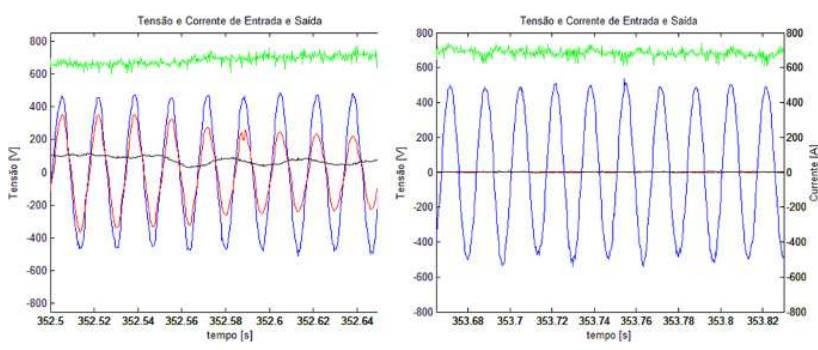

Figura 22: Formas de Onda para o Detalhe Negativo de Variação de Carga.

a forma de onda de corrente drenada do sistema apresenta certo conteúdo de terceira harmônica, e, a Fig. 27 apresenta o espectro harmônico desta corrente que está em plena conformidade com a norma IEC 61000-3-4.

Neste nível de potência, a forma de onda da corrente apresenta uma DHT $=13,2 \%, \mathrm{FP}=0,975,10,52^{\circ}$ de defasagem em relação a tensão e $95,4 \%$ de eficiência elétrica.

\section{CONCLUSÕES}

Esse artigo apresentou uma nova tecnologia para permitir a alimentação em corrente alternada de veículos tipo Trólebus, considerado como um sistema de tração elétrica não poluente, destinado ao transporte coletivo de pessoas em grandes centros urbanos.

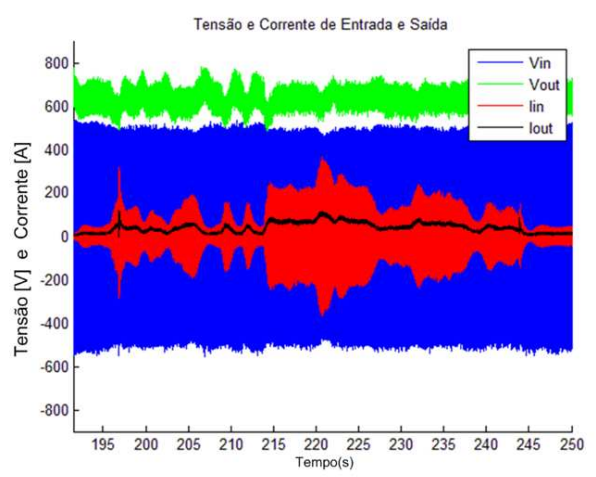

Figura 23: Tráfego Típico da Rede de Distribuição CA. 


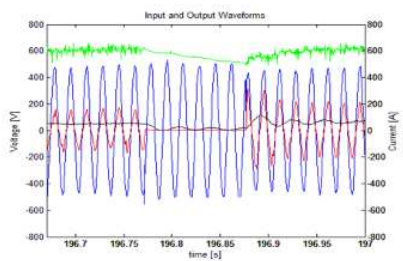

(a)

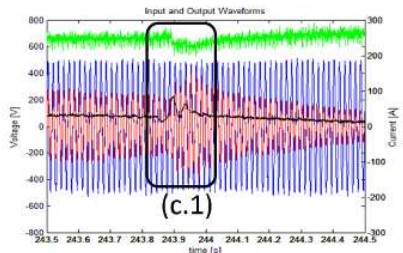

(c)

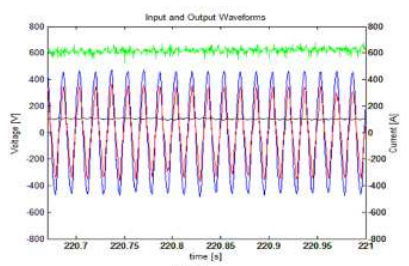

(b)

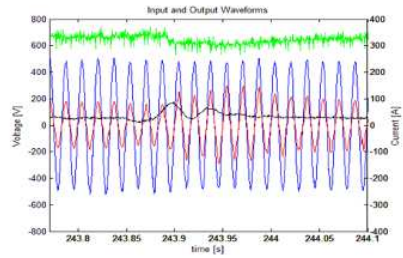

(c.1)
Figura 24: Detalhes das Formas de Onda da Figura 23.
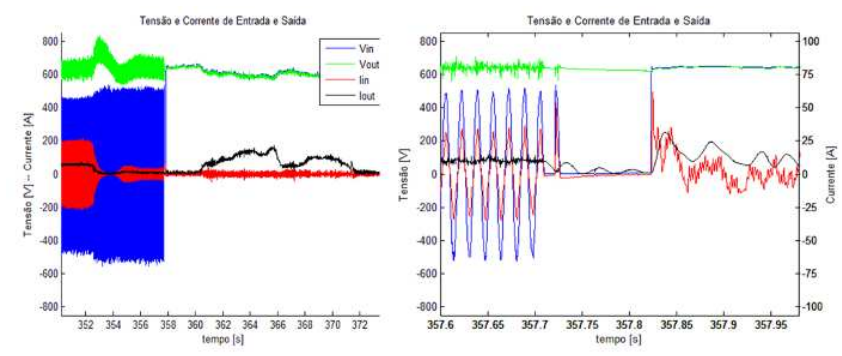

Figura 25: Mudança de Tipo de Rede de Distribuição de CA para CC.

A estrutura proposta inclui um retificador convencional não controlado em ponte completa associado a cinco conversores Boost entrelaçados, com potência nominal de $150 \mathrm{~kW}$, sendo o conjunto controlado através de um compensador PI não linear em conjunto com uma malha de controle de corrente antecipativa, mantendo elevado desempenho global e excelente estabilidade. A operação deste conversor como estágio pré-regulador retificador, quando da operação em CA, permite a correção do fator de potência, garantindo baixa DHT para a corrente de entrada, estando em total conformidade com a norma internacional IEC 61000-3-4.

Além disso, essa nova tecnologia é capaz de prover as mesmas condições operacionais para o veículo Trolebus, podendo este ser alimentado tanto por redes de distribuição aéreas em CA quanto por redes convencionais em CC, com comutação automática do modo de operação do conversor proposto.

Os resultados apresentados confirmam a possibilidade de expansão do sistema Trólebus de forma menos onerosa, em função do custo médio de instalação e manutenção de uma estação retificadora convencional para operação dos mesmos em CC, permitindo ainda o monitoramento e gerenciamento em tempo real do consumo de energia do veículo, e, a flexi-

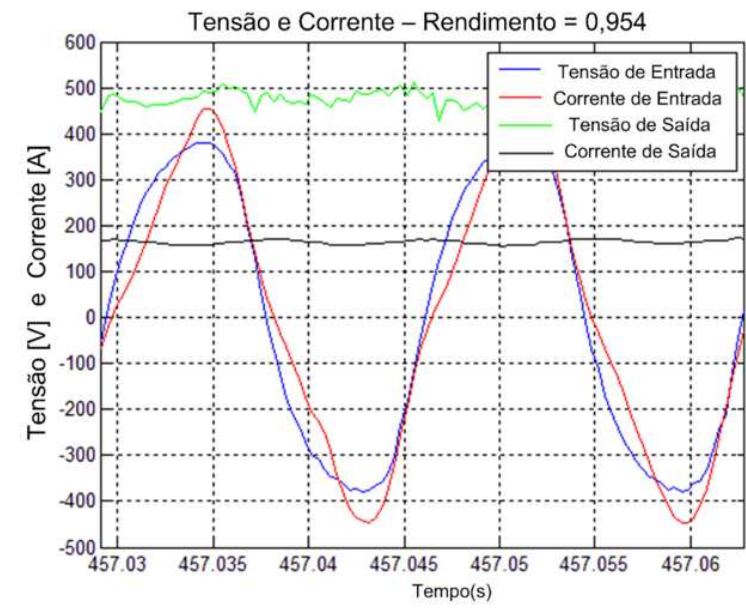

Figura 26: Formas de Onda Experimentais com Alta Potência Demandada.

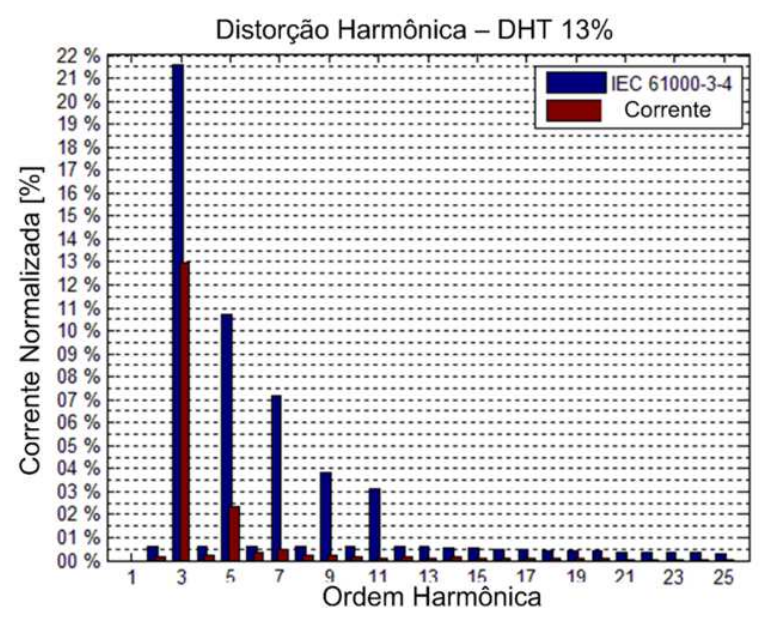

Figura 27: Espectro Harmônico da Corrente de Entrada apresentada na Figura 26.

bilidade de mudança entre os tipos de redes de distribuição, operando com alto fator de potência quando alimentado pela rede CA. Sustentam-se, desta forma, os grandes benefícios deste tipo de transporte coletivo no que se refere à redução do impacto ambiental, o que pode representar uma grande contribuição na redução dos índices de poluição nas áreas urbanas, principalmente nas cidades com alta densidade populacional.

Para as próximas décadas vislumbra-se ainda a completa eliminação das linhas aéreas e coletores tradicionais, adotandose postos de abastecimento em CA ao longo do trajeto, para carregamento e acumulação até o próximo posto, durante as paradas para embarque e desembarque de passageiros. 


\section{AGRADECIMENTOS}

Os autores agradecem à AES Eletropaulo Metropolitana Eletricidade de São Paulo S. A. pelo suporte financeiro concedido em conjunto com o programa de P\&D-ANEEL e à Himalaia Transportes S. A. pela cooperação e suporte, além da cessão do veículo Trólebus. Adicionalmente, os autores agradecem ao Sr. Jerry M. Muno e ao Sr. Marcelo dos Santos pelo suporte técnico dado durante os testes experimentais.

\section{REFERÊNCIA BIBLIOGRÁFICA}

A. Tustin (1947). A method of analyzing the behaviour of linear system in terms of time series. In: JIEE, Vol. 94, pt. IIA, pp. 130-142.

A. Fratta, P. Guglielmi, F. Villata and A. Vagati (1998). Efficiency and cost-effectiveness of AC drives for electric vehicles improved by a novel boost DC-DC conversion structure. In: Power Electronics in Transportation, pp. 11-19.

C. A. Canesin, F. A. S. Gonçalves, L. C. G. Freitas and G. A. Melo (2009a). HPF Boost Interleaved Operating in Discontinuous Conduction Mode for Trolleybus Application. In: Power Electronics Conference - COBEP, pp. $648-654$.

C. A. Canesin, F. A. S. Gonçalves, L. C. G. Freitas and G. A. Melo (2009b). DCM Boost Interleaved Converter for Operation in AC And DC to Trolleybus Application. In: European Conference on Power Electronics and Applications, 13, pp. 1-10.

C. A. Canesin, F. A. S. Gonçalves, L. C. G. Freitas, G. A. Melo and G. B. Lima (2009c). A novel single-phase HPF hybrid rectifier suitable for front-end trolleybus systems. In: Power Electronics Conference - COBEP, pp. 619-626.

C. A. Canesin, F .A. S. Gonçalves, L. C. G. Freitas, L. C. Freitas, G. A. Melo and G. B. Lima (2009d). Proposal of a hybrid rectifier structure with HPF and low THD suitable for front-end trolleybuses systems supplied by AC distribution networks. In: IEEE Energy Conversion Congress and Exposition, pp. 451 - 458.

D. B. TURNER and F. I. GUZMAN (1986). San Francisco MUNI Trolleybus Propulsion Tests: The Results. IEEE Transactions On Vehicular Technology, Vol. 35, No. 3, pp. 118-131.

F. A. S. Gonçalves and C. A. Canesin (2005) . A 2kW Interleaved ZCS-FM Boost Rectifier Digitally Controlled by FPGA Device. In: IEEE Power Electronics Specialists Conference, pp. 513-518.
G. C. Martin (1991). New York City Transit Authority's new technology test train program. In: IEEE Vehicular Technology Conference, pp. 875-880.

J. Michalik, J. Molnar and Z. Peroutka (2008). Control of traction single-phase current-source active rectifier under distorted power supply voltage. In: IEEE Power Electronics and Motion Control Conference, pp. 550555.

L. J. Brunton (1992). The Trolleybus History. IET Jornals, Vol. 38, No. 1, pp. $57-6$.

L. J. Brunton (2000). Why not the trolleybus? In: the IEE Seminar Electric, Hybrid and Fuel Cell Vehicles, pp. 17.

L. Zanotto, R. Piovan, V. Toigo, E. Gaio, P. Bordignon, T. Consani, M. Fracchia (2005). Filter design for harmonic reduction in high voltage booster for railway applications. IEEE Transactions on Power Delivery, Vol. 20, No.1, pp.258-263.

M. H. Erfanian and X. Wilsun (2008). An investigation on the effectiveness of Scott transformer on harmonic reduction. In: IEEE Power and Energy Society General Meeting - Conversion and Delivery of Electrical Energy, pp. 1-4.

M. Aeberhard, C. Courtois and P. Ladoux (2010). Railway traction power supply from the state of the art to future trends. In: International Symposium on Power Electronics Electrical Drives Automation and Motion - SPEEDAM, pp. 1350-1355.

P. Ladoux, A. lowinsky, P. Marino and G. Raimondo (2010). Reactive power compensation in railways using active impedance concept. In: International Symposium on Power Electronics Electrical Drives Automation and Motion - SPEEDAM, pp. 1362-1367

R. W. Erickson and D. Maksimović, 2001. Fundamentals of Power Electronics. 2. ed., Kluwer Academic Publisher, USA.

V. Grosjean (2009). Get wired (again): Trolleybus and Trolleytrucks. Low-teck Magazine. Disponível em: $<$ http://www.lowtechmagazine.com/2009/07/trolleytruckstrolleybuses-cargotrams.html $>$. Acesso em: 07 Abril 2010.

V. I. Sopov, V. V. Biryukov and G. N. Vorfolomeyev (2006). Increase of Efficiency of the Power Supply System of a Trolleybus. In: IEEE IFOST, pp. 336-337.

W. Czuchra, W. Mysinski and W. Zajac (2009). Modelling and testing of RFI filter for a trolleybus transistor inverter. European Conference on Power Electronics and Applications, 13, pp. 1-9. 